\title{
Self-healing cementitious materials by the combination of microfibres and superabsorbent polymers
}

Journal of Intelligent Material Systems and Structures

20।4, Vol 25(I) I3-24

(C) The Author(s) 2012

Reprints and permissions:

sagepub.co.uk/journalsPermissions.nav DOI: I0.1 I77/I045389XI2438623 jim.sagepub.com (SAGE

\author{
Didier Snoeck', Kim Van Tittelboom', Stijn Steuperaert ${ }^{2}$, Peter Dubruel ${ }^{2}$ \\ and Nele De Belie'
}

\begin{abstract}
Concrete cracks due to its low tensile strength. The presence of cracks endangers the durability as they generate a pathway for harmful particles dissolved in fluids and gases. Without a proper treatment, maintenance costs will increase. Self-healing can prevail in small cracks due to precipitation of calcium carbonate and further hydration. Therefore, the use of microfibres is proposed to control the crack width and thus to promote the self-healing efficiency. In the current research, crack sealing is also enhanced by the application of superabsorbent polymers. When cracking occurs, superabsorbent polymers are exposed to the humid environment and swell. This swelling reaction seals the crack from intruding potentially harmful substances. Mortar mixtures with microfibres and with and without superabsorbent polymers were investigated on their crack sealing and healing efficiency. Regain in mechanical properties upon crack healing was investigated by the performance of four-point-bending tests, and the sealing capacity of the superabsorbent polymer particles was measured through a decrease in water permeability. In an environment with a relative humidity of more than $60 \%$, only samples with superabsorbent polymers showed healing. Introducing I $\mathrm{m} \%$ of superabsorbent polymer gives the best results, considering no reduction of the mechanical properties in comparison to the reference, and the superior self-sealing capacity.
\end{abstract}

\section{Keywords}

Autogenous crack healing, mortar, four-point-bending, multiple cracking, hydrogel, water permeability, thermogravimetric analysis, calcium carbonate

\section{Introduction}

Cracking in concrete occurs commonly due to the relatively low tensile strength. However, concrete has a passive healing capacity of its own, also called autogenous healing. Unhydrated cement particles always remain present in a hardened concrete matrix. As water flows into the cracks, continued hydration of these unhydrated cement grains produces new calcium silicate hydrate $(\mathrm{C}-\mathrm{S}-\mathrm{H})$, which can result in sealing of small cracks. Another mechanism of autogenous crack healing is the precipitation of calcium carbonate $\left(\mathrm{CaCO}_{3}\right)$, which also blocks the crack. These forms of crack healing are studied in detail by Edvardsen (1999) who observed a decrease in water permeability in cracked concrete specimens due to autogenous crack healing. Lepech (2006) also proved autogenous crack sealing by the precipitation of $\mathrm{CaCO}_{3}$ by means of energy-dispersive $\mathrm{X}$-ray spectroscopy as a decrease in water permeability in time was noticed.

Edvardsen (1999) suggested that autogenous healing was mainly caused by the precipitation of $\mathrm{CaCO}_{3}$; however, Granger et al. (2007) ascribed healing to the further hydration of cement particles and by the formation of new strong $\mathrm{C}-\mathrm{S}-\mathrm{H}$ crystals. Homma et al. (2009) and ter Heide (2005) addressed healing to the combination of (a) further reaction of the hitherto unhydrated cement; (b) closing of the cracks due to blocking by cement particles, hydration particles, loose particles and impurities; (c) expansion of the $\mathrm{C}-\mathrm{S}-\mathrm{H}$ in concrete at the crack faces; and (4) precipitation of $\mathrm{CaCO}_{3}$ by the mechanisms given in equations (1) and (2) (Edvardsen, 1999).

\footnotetext{
'Magnel Laboratory for Concrete Research, Department of Structural Engineering, Faculty of Engineering, Ghent University, Ghent, Belgium

${ }^{2}$ Polymer Chemistry and Biomaterials Group, Department of Organic Chemistry, Faculty of Sciences, Ghent University, Ghent, Belgium
}

\section{Corresponding author:}

Nele De Belie, Magnel Laboratory for Concrete Research, Department of Structural Engineering, Faculty of Engineering, Ghent University, Technologiepark Zwijnaarde 904, B-9052 Ghent, Belgium. Email: nele.debelie@UGent.be 


$$
\begin{aligned}
& 8<\mathrm{pH}_{\text {water }} \mathrm{Ca}^{2+}+\mathrm{CO}_{2}+2 \mathrm{OH}^{-} \rightarrow \mathrm{CaCO}_{3}+\mathrm{H}_{2} \mathrm{O} \\
& 7<\mathrm{pH}_{\text {water }}<8 \mathrm{Ca}^{2+}+\mathrm{HCO}_{3}^{-} \rightarrow \mathrm{CaCO}_{3}+\mathrm{H}^{+}
\end{aligned}
$$

$\mathrm{Ca}^{2+}$ ions in the matrix react with carbon dioxide $\left(\mathrm{CO}_{2}\right)$ or hydrogen carbonate $\left(\mathrm{HCO}_{3}{ }^{-}\right)$dissolved in water to form $\mathrm{CaCO}_{3}$. The crystallisation rate within the crack is dependent on the crack width and the water pressure but independent of the concrete composition and the type of water (Edvardsen, 1999).

There are three needed conditions for autogenous crack healing to occur. These are the presence of specific chemical ions (e.g. $\mathrm{Ca}^{2+}, \mathrm{CO}_{2}$ ), the exposure to humid environmental conditions (e.g. wet/dry cycles, submersion in water) and small crack widths $(<50$ $150 \mu \mathrm{m})$. According to Yang (2008), cracks smaller than $50 \mu \mathrm{m}$ show complete healing, and cracks smaller than $150 \mu \mathrm{m}$ show only partial healing. From the latter, it can be concluded that autogenous healing is only efficient for healing of narrow cracks. However, a dedicated material design can promote the autogenous healing capacity. Two possible mechanisms and their combined effect are investigated in this study.

The first mechanism is the introduction of microfibres to obtain fibre-reinforced cementitious materials with a high tensile ductility, as studied by Yang (2008) and $\mathrm{Li}$ (2008). These composites exhibit a tensile strainhardening behaviour achieved by matrix multiple cracking (MC). The crack width is limited to $20-80$ $\mu \mathrm{m}$, which gives the best opportunity for self-healing. The main purpose of the fibres is to provide a controlled way of cracking and to increase the fracture toughness of the brittle cementitious matrix through bridging action during both micro- and macrocracking of the matrix. Self-healing prevails in a variety of environmental conditions even when the composite is deliberately damaged by tensioning to several percentages strain. In air (this means, without the presence of water), the composite does not heal (Yang, 2008).

The second healing mechanism is the use of reactive substances. Hydrogels, or superabsorbent polymers (SAPs), have the ability to absorb a significant amount of liquid from the surrounding environment (up to 500 times their own weight) and to retain the liquid within their structure without dissolving. SAPs in concrete have proven their use in decreasing the autogenous shrinkage (Jensen and Hansen, 2001, 2002). Brüdern and Mechtherine (2010) showed (in uncracked concrete) internal curing due to the presence of SAPs and a decrease of the autogenous shrinkage and selfdesiccation by the gradual release of water from the SAP particles. Mönnig (2009) visualised the densification of the matrix around a SAP particle due to the larger amount of water available in time. Lee et al. (2010) investigated the incorporation of SAPs in concrete in order to obtain self-sealing properties. When liquids enter a crack, SAP particles along the crack faces will swell and block the crack. Kim and Schlangen (2011) showed that SAPs can contribute to the internal healing of a crack. By absorbing fluids from the surroundings, water is available for healing. The formation of new cracks was noticed upon reloading the samples containing SAPs, and regain of mechanical properties was shown. Specimens containing SAPs cured in air showed almost no healing. The aim of the current research is to investigate the ability of two types of SAPs to promote self-sealing and self-healing in microfibre-reinforced concrete under realistic conditions of wet-dry cycles and in air with medium or high relative humidity.

\section{Materials and methods}

\section{Materials}

The studied mortar mixtures were composed of ordinary portland cement (CEM I $52.5 \mathrm{~N} ; 571 \mathrm{~kg} / \mathrm{m}^{3}$ ), fly ash $\left(685 \mathrm{~kg} / \mathrm{m}^{3}\right)$, silica sand $0 / 2\left(456 \mathrm{~kg} / \mathrm{m}^{3}\right)$, water $(332 \mathrm{~kg} /$ $\mathrm{m}^{3}$ ), a polycarboxylate superplasticiser (Glenium 51, concentration $35 \%$ ), several volume percent of fibres and a varying amount of SAPs expressed as mass $\%(\mathrm{~m} \%)$ of cement weight (Table 1). Two types of SAPs from the company BASF (BASF Construction Chemicals GmbH, Trostberg, Germany) were used. These include SAP A, a copolymer of acrylamide and sodium acrylate (particle size $100.0 \pm 21.5 \mu \mathrm{m}$ ), and SAP B, a cross-linked potassium salt polyacrylate (particle size $476.6 \pm 52.9 \mu \mathrm{m}$ ). All SAPs were vacuum dried in a desiccator with silica gel with a relative humidity $(\mathrm{RH})$ of $3 \%$ prior to testing.

Series used for four-point-bending tests consisted of three $160 \times 40 \times 15 \mathrm{~mm}^{3}$ samples with 2 vol. $\%$ of $6 \mathrm{~mm}$ polyvinyl alcohol (PVA) fibres from the Belgian company Redco (Redco NV, Kapelle-op-den-Bos, Belgium). The cylindrical samples used in the permeability tests were $78 \mathrm{~mm}$ in diameter and $20 \mathrm{~mm}$ high and had 1 vol.\% PVA fibres of Redco. A minimum of three samples was always tested to receive statistical relevant results. The studied mortar mixtures with their composition and curing conditions are listed in Table 1.

\section{Absorption kinetics}

To assess the sealing capacity of the superabsorbent polymers, the swelling capacity was calculated from the volume increase between the vacuum-dried state and the saturated state. A fluid was added to vacuum-dried SAP particles, and the whole was filtered after 1 day. The amount of filtered fluid was recorded. To ensure there was no influence of the filter paper, the latter was saturated with the fluid prior to filtration. The volume increase of the SAP was measured as the difference between the added water and the filtered water. This volume increase is a measurement for the total 
Table I. Studied mortar samples with their code, $V_{f}$ of PVA fibres, $m \%$ of SAP, method of crack formation, curing conditions and number of specimens tested.

\begin{tabular}{|c|c|c|c|c|c|c|}
\hline Specimen & Code & $v_{f}$ & $\mathrm{~m} \% \mathrm{SAP}$ & Cracking & Curing & Number \\
\hline \multirow{9}{*}{ Prism } & REF & 2 & 0 & 4-point bending & Wet/dry cycles & 3 \\
\hline & P90 & 2 & 0 & 4-point bending & $\mathrm{RH}>90 \%$ & 3 \\
\hline & $\mathrm{P} 60$ & 2 & 0 & 4-point bending & $\mathrm{RH}=60 \%$ & 3 \\
\hline & Al & 2 & I & 4-point bending & Wet/dry cycles & 3 \\
\hline & $\mathrm{BI}$ & 2 & i & 4-point bending & Wet/dry cycles & 3 \\
\hline & B90 & 2 & i & 4-point bending & $\mathrm{RH}>90 \%$ & 3 \\
\hline & $\mathrm{B} 60$ & 2 & I & 4-point bending & $\mathrm{RH}=60 \%$ & 3 \\
\hline & B2 & 2 & 2 & 4-point bending & Wet/dry cycles & 3 \\
\hline & B4 & 2 & 4 & 4-point bending & Wet/dry cycles & 3 \\
\hline \multirow{6}{*}{ Cylinder } & REF & 1 & 0 & Splitting & Permeability & 5 \\
\hline & Al & 1 & I & Splitting & Permeability & 5 \\
\hline & B0.5 & 1 & 0.5 & Splitting & Permeability & 5 \\
\hline & $\mathrm{BI}$ & I & 1 & Splitting & Permeability & 3 \\
\hline & B2 & 1 & 2 & Splitting & Permeability & 4 \\
\hline & B4 & 1 & 4 & Splitting & Permeability & 4 \\
\hline
\end{tabular}

SAP: superabsorbent polymer; RH: relative humidity; PVA: polyvinyl alcohol.

Table 2. Mean absorption of SAP and standard deviation ( $g$ fluid/g SAP) $(n=3)$ for several solutions with their $\mathrm{pH}$ and absorption determined in a dynamic vapour sorption test in air of $100 \% \mathrm{RH}$ (g moisture/g SAP).

\begin{tabular}{lrrr}
\hline Method & $\mathrm{PH}$ & SAP A & SAP B \\
\hline$\Delta V$ deionised water & 6.5 & $305.0 \pm 3.7$ & $283.2 \pm 2.4$ \\
$\Delta V$ tap water & 6.8 & $163.9 \pm 1.2$ & $148.9 \pm 0.9$ \\
$\Delta V$ NaOH solution & 13.0 & $72.5 \pm 0.9$ & $68.4 \pm 0.7$ \\
$\Delta V$ cement slurry & 12.8 & $61.0 \pm 1.0$ & $58.4 \pm 1.7$ \\
$\Delta V$ seawater & 6.3 & $30.0 \pm 0.8$ & $28.3 \pm 0.9$ \\
$\Delta V$ HCl solution & 2.5 & $13.6 \pm 0.5$ & $12.7 \pm 0.5$ \\
Dynamic vapour sorption & & 1.68 & 1.50
\end{tabular}

SAP: superabsorbent polymer; RH: relative humidity.

absorption. Several different fluids can enter a crack of a structure during its lifetime. Therefore, the measurements were performed in deionised water as well as in tap water, a diluted $\mathrm{NaOH}$ solution, a filtered cement slurry (obtained by mixing $20 \mathrm{~g}$ OPC in $200 \mathrm{~g}$ of water), artificial seawater (with $24 \mathrm{~g} \mathrm{NaCl}, 5 \mathrm{~g} \mathrm{MgCl}_{2}, 4 \mathrm{~g}$ $\mathrm{Na}_{2} \mathrm{SO}_{4}, 0.7 \mathrm{~g} \mathrm{CaCl}_{2}$ and $0.8 \mathrm{~g} \mathrm{MgBr}_{2}$ for $1 \mathrm{~L}$ seawater) and a diluted $\mathrm{HCl}$ solution. The solutions together with their $\mathrm{pH}$ values are listed in Table 2 .

The water absorption of SAP B, which is spherical, was also investigated by means of optical microscopy (Leica S8 APO (Leica Microsystems BVBA, GrootBijgaarden, Belgium)) and subsequent image analysis. With a syringe, water was carefully and gradually added to the SAPs until an individual SAP particle became saturated. The absorption was calculated as the volume increase relative to the original volume in the dry state, divided by the relative density of the SAPs and fluid and expressed as gram fluid absorbed per gram SAP (Tanaka and Fillmore, 1979). SAP A particles were too small, and the time needed to fully saturate SAP A was considerable, so microscopic analyses were not performed for SAP A.
The values found for the absorption of SAPs in contact with fluid were compared to water sorption in a $100 \%$ RH environment, during dynamic vapour sorption (DVS) measurements (Surface Measurement Systems, London, UK). For the DVS analysis, approximately $0.01-0.02 \mathrm{~g}$ of dry SAPs (taken from the desiccator) were put on a dish placed in the chamber where the desired level of RH was obtained by mixing a proportional amount of dry and humid nitrogen gas. During the first step, the sample was vacuum dried and subjected to $0 \% \mathrm{RH}$. The humidity was then changed in steps of $20 \%$, each time the change of the sample mass in time was lower than 0.002 wt. $\%$ per minute till the target value of $100 \%$ $\mathrm{RH}$ was reached. Then the $\mathrm{RH}$ was decreased using the same value of the mass change in time as a criterion and a $20 \%$ RH step till the complete desorption curve was obtained. The equilibrium values at $100 \%$ RH were computed from the weight versus time curves by extrapolation using the exponential function presented in equation (3).

$$
m(t)=a \cdot(1-b \cdot \exp (-c \cdot t))
$$


where $m(t)$ is the mass of the sample at time $t$ of the measurement, and coefficients $a, b$ and $c$ are determined by means of non-linear curve fitting.

\section{Mixing procedure}

The first step in the mixing procedure was dry mixing of all the solid components (cement, fly ash, silica sand and for some mixes SAPs) with a standard mortar mixer. Water was then added to the dry mixture during $10 \mathrm{~s}$, and the mixture was further mixed during $1 \mathrm{~min}$ at $140 \mathrm{rpm}$. The superplasticiser was then added, and the composition was again mixed during $1 \mathrm{~min}$. The edges of the bowl were scraped during $30 \mathrm{~s}$, and the mixing velocity was altered to $285 \mathrm{rpm}$. The mixture was mixed during five more minutes until it became homogenous. When the mixture was consistent and uniform, the fibres were slowly added during 2 min mixing at 140 $\mathrm{rpm}$. The mixture was mixed during one more minute at $140 \mathrm{rpm}$ and $3 \mathrm{~min}$ at $285 \mathrm{rpm}$. Moulds were filled, and the samples were compacted by placing the moulds on a vibration table for $2 \mathrm{~min}$. The samples were demoulded after $24 \mathrm{~h}$ and were stored at a $\mathrm{RH}$ of more than $90 \%$ and a temperature of $20 \pm 2^{\circ} \mathrm{C}$ until the age of 28 days.

\section{Four-point-bending test}

By means of a displacement-controlled four-pointbending test, multiple cracks were created in the mortar prisms at an age of 28 days (Figure 1). The servo hydraulic testing system (DB 250/15; Walter + Bai (Walter + Bai AG, Löhningen, Switzerland)) ensured a displacementcontrolled test $(0.002 \mathrm{~mm} / \mathrm{s}$ to imitate a quasi-static load). The displacement was increased until the maximum MC capacity was reached. Several cracks were formed $(6-50 \mu \mathrm{m})$ together with one large final crack of approximately 100-150 $\mu \mathrm{m}$. Force-displacement curves obtained through the software Proteus ${ }^{\circledR} 10.1$ (Walter + Bai AG, Löhningen, Switzerland) were transformed into stress-strain curves by relating the vertical displacement to the strain in the curved lower surface of the prisms during bending by means of trigonometry.

After MC, the samples were cured for another 28 days under three different conditions: (a) wet/dry cycles
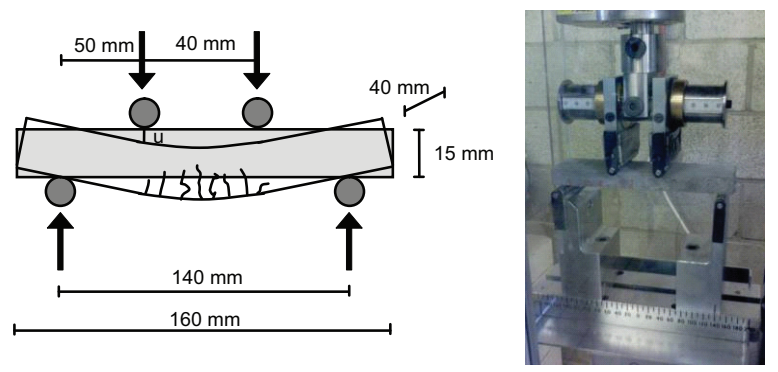

Figure I. Schematisation of the test setup and testing machine used for the four-point-bending test. during which samples were stored alternately for 1 day in water and 1 day in air at a $\mathrm{RH}$ of $60 \%$, (b) a $\mathrm{RH}$ of more than $90 \%$ and (c) a RH of $60 \%$. After a period of 28 days, the specimens were tested again in a fourpoint-bending test, and the mechanical properties obtained during the first and the second loading cycles were compared. In between both loading cycles, microscopic observations were performed by means of a stereomicroscope (Leica S8 APO).

The parameters investigated in the stress-strain curves were the stress at the point of formation of the first crack, further called first-cracking strength $\left(\sigma_{f c}\right)$, the peak stress $\left(\sigma_{c u}\right)$ and the strain increase over the hardening branch as a measurement of the MC (Figure 2). The preloading was manually stopped at the release stress $\left(\sigma_{\text {release }}\right)$, which was smaller than $\sigma_{f c}$ to ensure a maximum use of MC. In the strain-hardening area of the curve (MC), some drops in stress are visible (indicated with grey arrows). These represent the MC pattern. The self-healing capacity was determined as the regain of $\sigma_{f c}, \sigma_{c u}$ and $\mathrm{MC}$. The equations used are equations (4) to (6), respectively.

$$
\begin{array}{cl}
\text { Regain of } \sigma_{f c} & \frac{\sigma_{f c, \text { reloading }}-\sigma_{\text {release }}}{\sigma_{f c, \text { preloading }}-\sigma_{\text {release }}} \\
\text { Regain of } \sigma_{c u} & \frac{\sigma_{c u, \text { reloading }}-\sigma_{\text {release }}}{\sigma_{c u, \text { preloading }}-\sigma_{\text {release }}} \\
\text { Regain of MC } & \frac{\mathrm{MC}_{\text {reloading }}}{\mathrm{MC}_{\text {preloading }}}
\end{array}
$$

\section{Water permeability}

The decrease in water permeability is a measure for the sealing capacity. Permeability tests were carried out after cracking cylindrical specimens with an age of 7 days by means of a crack width-controlled splitting test (Walter + Bai DB 250/15 (Walter + Bai AG, Löhningen, Switzerland)), following the method described by Aldea et al. (1999) and Van Tittelboom et al. (2011). The crack width was controlled with one linear variable difference transducer (LVDT) (Solartron AX/0.5/S (Solartron Metrology, West Sussex, UK) with an accuracy of $1 \mu \mathrm{m}$ ), as can be seen in Figure 3 . The crack opened with a velocity of $0.001 \mathrm{~mm} / \mathrm{s}$, and splitting was stopped when a $300 \mu \mathrm{m}$ crack width was reached. After splitting, the samples were glued with epoxy into a polyvinyl chloride (PVC) tube to exclude the side effects during the permeability tests. These samples were vacuum saturated with deionised water and placed into the water permeability test setup at an age of 28 days. After unloading, the residual crack width was about $150-200 \mu \mathrm{m}$.

The self-healing efficiency was measured as the decrease in water flow over time. Starting from Darcy's law, an expression for the coefficient of water permeability $k(\mathrm{~m} / \mathrm{s})$ is found in equation (7). 


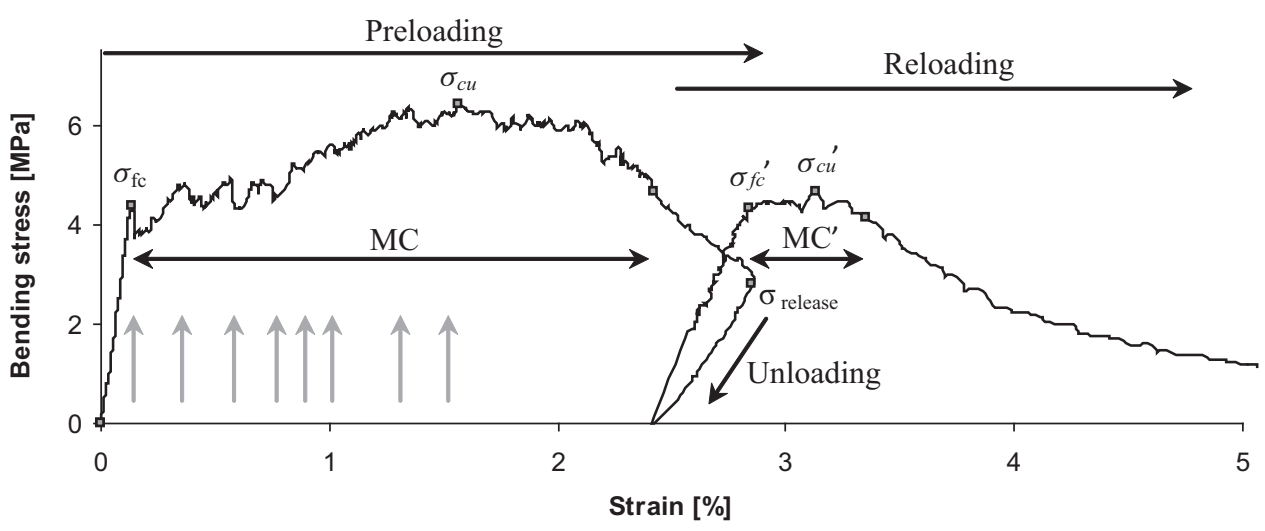

Figure 2. Schematisation of the investigated mechanical properties in a typical stress-strain curve, with the formation of the multiple cracking pattern (grey arrows).
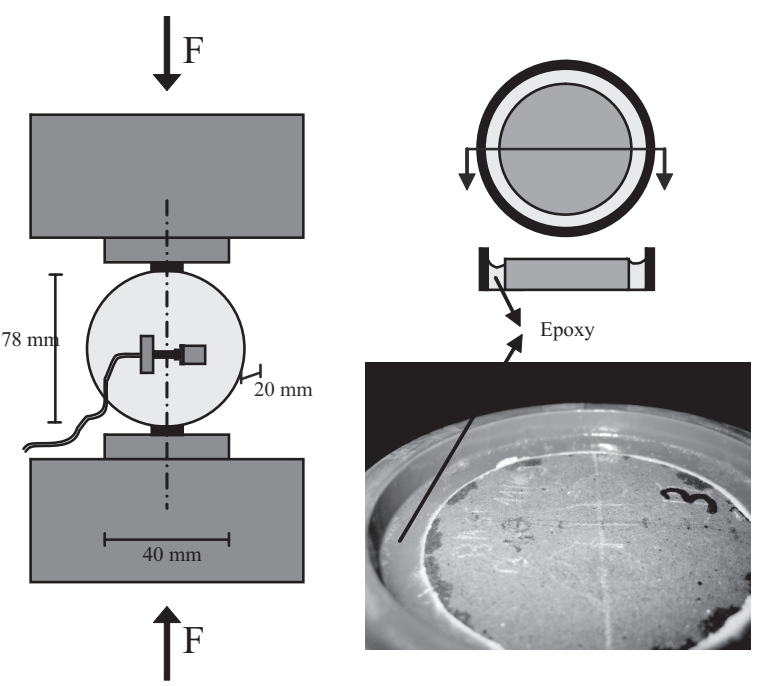

Figure 3. Schematisation of the test setup used for a crackcontrolled splitting test and sample preparation for the water permeability test.

$$
k=\frac{a \cdot L}{A \cdot t_{f}} \cdot \ln \left(\frac{h_{0}}{h_{f}}\right)
$$

where $a$ is the cross-sectional area of the fluid column $\left(\mathrm{m}^{2}\right), L$ is the thickness of the specimen $(\mathrm{m}), A$ is the surface area of the sample subjected to the flow $\left(\mathrm{m}^{2}\right), t_{f}$ is the measured time $(\mathrm{s}), h_{0}$ is the initial pressure head (m) and $t_{f}$ is the remaining pressure head (m).

Permeability readings for all specimens were taken every day. Because the measurements were not immediately constant, they were repeated until a steady-state flow was reached. This steady-state flow was reached when subsequent measurements were almost constant in time. During the measurements, the specimens remained completely submerged. On the 30th day (at an age of 58 days), the average coefficients of water permeability of the samples were compared.

The relationship between $k$ and the crack width $w(\mathrm{~m})$ is based on equation (8). This equation is derived by Tsukamoto and Woener (1991) according to a parallel-plate theory of fluid dynamics. The parallelplate theory assumes an incompressible fluid where the laminar flow is fully developed. The water permeability coefficient $k$ is a function of $w$ to the third power, so only the largest crack at the inlet side of the specimen in the water permeability test is of significance.

$$
k=\frac{a_{g} \cdot I \cdot l_{s} \cdot g}{12 \cdot \nu} \cdot w^{3}
$$

where $a_{g}$ is a flow rate coefficient indicating the smoothness of the crack surface as the concrete faces are not parallel $\left(0 \leqslant a_{g} \leqslant 1\right)(-), I$ is the pressure gradient $(\mathrm{h} / \mathrm{d})(-)$, $h$ is the height of the fluid column on the inlet (m), $d$ is the length of the crack in the flow direction $(\mathrm{m}), l_{s}$ is the length of the crack at a right angle to the flow direction (m), $g$ is the gravity constant $\left(\mathrm{m} / \mathrm{s}^{2}\right)$ and $\nu$ is the kinematic viscosity $\left(\mathrm{m}^{2} / \mathrm{s}\right)$. The real boundaries in literature for $a_{g}$ are 0.04 and 0.53 (Edvardsen, 1999). Edvardsen (1999) calculated a value of 0.25 for $a_{g}$. Homma et al. (2009) stated that the formula of Tsukamoto had a high variability in the small crack width range. In this study, the crack widths exceed the $100-\mu \mathrm{m}$ boundary given by Homma et al. (2009), and therefore, the formula of Tsukamoto is assumed to be valid.

The formula states that the permeability increases with the third power of the crack width. By dividing the water permeability coefficient $k$ by $w^{3}$, all fluctuations of the crack width of the specimens are taken into account. Subsequently, only the effect of SAPs on the sealing efficiency is investigated.

\section{Microscopic and thermogravimetric analysis}

A microscopic analysis was used to examine the cracks and measure the decrease in crack width due to healing. The stereomicroscope used was a Leica S8 (Leica Microsystems BVBA, Groot-Bijgaarden, Belgium) APO with DFC 295 camera. An image analysis was performed by the software Leica ${ }^{\circledR}$. 


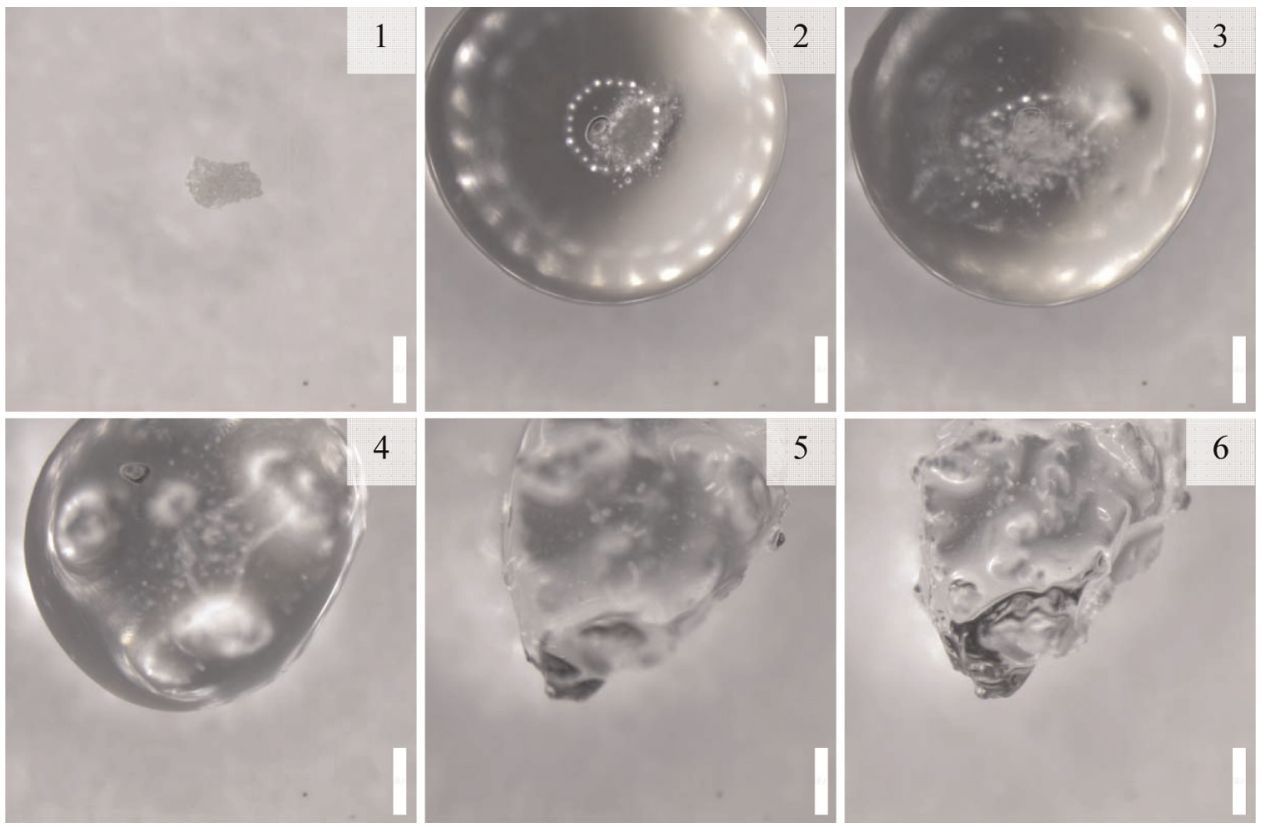

Figure 4. Visualisation of the absorption of a SAP B particle with steps of $10 \mathrm{~s}$. The scale bars on the bottom right have a height of $500 \mu \mathrm{m}$.

SAP: superabsorbent polymer.

A thermogravimetric analysis (TGA) with a Hi-Res TGA 2950 Thermogravimetric Analyser (TA Instruments NV/SA, Zellik, Belgium) was conducted to determine the composition of the white crystallisation found in the permeability tests and the degradation temperature of pure SAP. The crystals were carefully removed from the specimens, and approximately $0.01 \mathrm{~g}$ was used in the TGA. During the analysis, the temperature was gradually increased $\left(10^{\circ} \mathrm{C} / \mathrm{min}\right)$, and the mass decrease was measured by a Cahn microbalance until a temperature of $1000^{\circ} \mathrm{C}$ was reached. The measurements were performed under a controlled helium atmosphere.

\section{Statistical analysis}

A statistical analysis was performed using the program SPSS $^{\circledR}$ (IBM International Business Machines Corporation, New-York, United States). Multiple averages were compared using an analysis of variance (ANOVA) test with a significance level of 5\%. The homogeneity of the variances was controlled with a Levene's test. The post hoc test for data with homogenous variances was a Student-Newman-Keuls test and if no homogenous variances were obtained, a Dunnett's T3 test was used.

\section{Results and discussion}

\section{Absorption kinetics}

The values for SAPs A and B are in accordance with the absorption values found in the literature for acrylic SAPs (approximately $350 \mathrm{~g} / \mathrm{g}$ in distilled water, $37 \mathrm{~g} / \mathrm{g}$ in synthetic pore fluid and $3 \mathrm{~g}$ moisture/ g SAPs with $\mathrm{RH}=100 \%$ after Jensen and Hansen (2001, 2002)) (Table 2). The absorption in filtered cement slurry is lower than in deionised water due to the charge screening effect resulting from the cations $\mathrm{K}^{+}, \mathrm{Na}^{+}, \mathrm{Mg}^{2+}$ and $\mathrm{Ca}^{2+}$ in the slurry. Therefore, the ionic repulse of the negatively charged acrylic groups is lower and thus the absorption decreases. SAP particles consist of large chains cross-linked at certain points. Due to the ionic repulsion of the fluid and the acrylic groups of the SAP, the SAP particles swell. The value of absorption increases in the following order of fluids: $\mathrm{HCl}$ solution, artificial seawater, filtered cement slurry, $\mathrm{NaOH}$ solution, tap water and deionised water. The main reason for this is the screening effect of the above-mentioned cations.

SAP B was almost spherical, so the absorption could also be determined by microscopic investigations. The absorption obtained in this way was $282.66 \pm 7.51 \mathrm{~g}$ deionised water/g SAP and $57.96 \pm 3.05 \mathrm{~g}$ cement slurry/g SAP. Physical forces between SAP particles can distort the value of absorption obtained from the teabag method. In the latter method, SAP particles are placed in a teabag and submerged into a liquid. As the SAP cannot leave the teabag, the increase in mass after immersion is a measure for the absorption capacity. The absorption values found by microscopic investigation of one single SAP particle are not significantly different from those listed in Table 2, which are obtained by the filtration method. This shows that the absorption capacity obtained from filtration is a realistic value of absorption, and the effect of physical forces between the SAPs is negligible. 


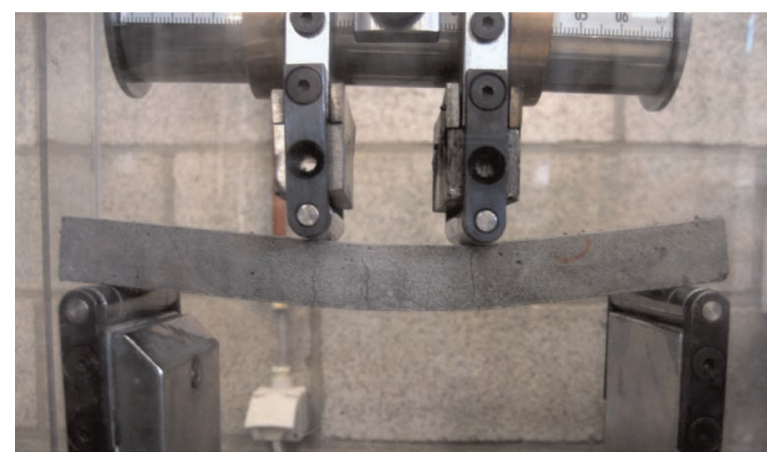

Figure 5. Four-point-bending test on a specimen containing 2 vol.\% of PVA fibres showing a vertical displacement of $7 \mathrm{~mm}$. The total height of the specimen is $15 \mathrm{~mm}$. PVA: polyvinyl alcohol.
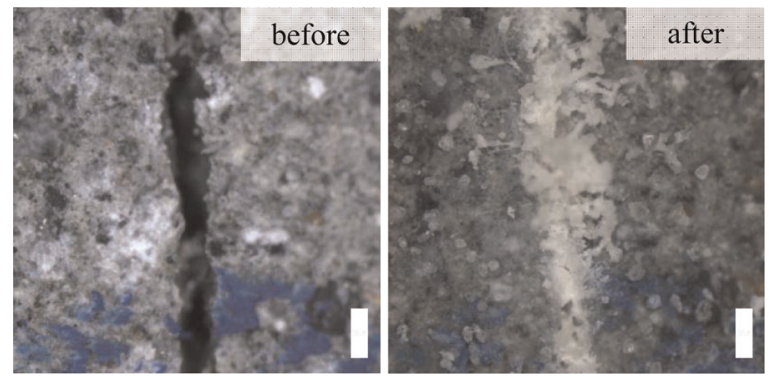

Figure 6. Total healing of a $138-\mu \mathrm{m}$ crack of a specimen containing I m\% SAP B after wet/dry cycles. The scale bars have a height of $200 \mu \mathrm{m}$.

SAP: superabsorbent polymer.

DVS measurements showed a low moisture uptake in a RH of $100 \%$. Still, SAPs manage to take up about 1.5 times their own weight in moisture. This value seems to be negligible, but as further results will point out, the moisture uptake is important to sustain healing.

A visualisation of the absorption of a SAP B particle is shown in Figure 4 with steps of $10 \mathrm{~s}$. In this visualisation, a single water droplet was placed on the SAP. The outer parts of a SAP particle take up the fluid and open the path for the inner part of the SAP to absorb water. The droplet of water is absorbed, and the total absorption is still not reached. Afterwards, small droplets were carefully added until the SAP became saturated.

\section{Four-point-bending test}

When 2 vol.\% PVA fibres were mixed in, the amount of $\mathrm{MC}$ and the ductility of the specimen were noteworthy (Figure 5). When a crack forms, bridging action of the fibres takes over. The stress can be augmented and the sample cracks elsewhere. This process continues until the weakest link becomes the fibre bridging action instead of the strength of the cementitious matrix. Then, a previously opened crack widens, and the composite has reached its final possible strain. This phenomenon is named MC. A maximum of $7 \mathrm{~mm}$ vertical displacement was manageable, and the corresponding crack width varied between 6 and $104 \mu \mathrm{m}$. It was also shown that it was possible to heal cracks within this range. Eight to nine small healable cracks were formed instead of a single large unhealable crack. Microfibre-reinforced composites had crack widths between 20 and $80 \mu \mathrm{m}(\mathrm{Li}, 2008)$ when oil-coated PVA fibres were used. In this investigation, uncoated PVA fibres were used. Therefore, there was a better bound with the cement matrix, and thus, a lower crack width range $(6-36 \mu \mathrm{m})$ as fibre tunnelling was more restricted. After MC, one previously formed crack opened, thus resulting in the 6 to $104 \mu \mathrm{m}$ crack width range.

Cracks smaller than $30 \mu \mathrm{m}$ exposed to wet/dry cycles healed completely both with and without SAPs. Cracks between 50 and $150 \mu \mathrm{m}$ healed partly in samples without SAPs, but for samples containing SAP B, even a 138- $\mu \mathrm{m}$ crack closed completely (Figure 6). On the inner part of the crack faces, the same white material was noticed at the surface, which can be attributed to the precipitation of $\mathrm{CaCO}_{3}$. Cracks larger than $200 \mu \mathrm{m}$ showed no healing. This is more or less in correspondence with the findings of Yang (2008) on the same mixture without SAPs, who observed total healing of cracks smaller than $50 \mu \mathrm{m}$ and partial healing of cracks up to $150 \mu \mathrm{m}$.

Internal curing by means of SAPs has a positive influence on the amount of regain in mechanical properties. SAPs can sustain hydration by yielding their absorbed water and provide water for the precipitation of $\mathrm{CaCO}_{3}$ and for the formation of new $\mathrm{C}-\mathrm{S}-\mathrm{H}$ crystals. The stimulation of cement hydration is visible in the densification of the cementitious matrix around a SAP particle, as shown in Figure 7.

The precipitation of $\mathrm{CaCO}_{3}$ is facilitated by the microfibres as they act as a nucleation site where the

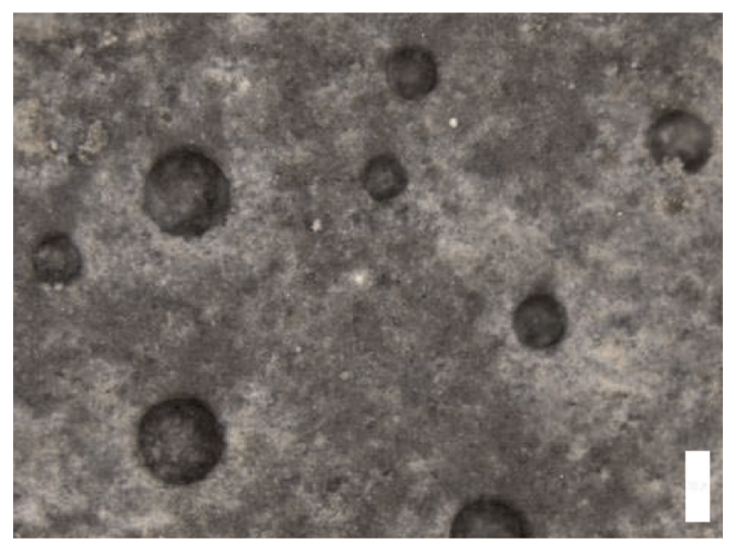

Figure 7. Densification of the cementitious matrix around SAP particles. The scale bar has a height of $500 \mu \mathrm{m}$.

SAP: superabsorbent polymer. 


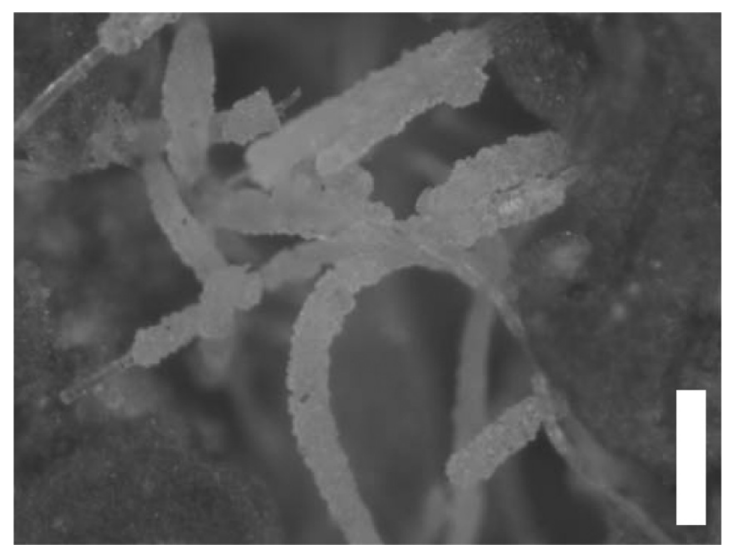

Figure 8. Attachment of $\mathrm{CaCO}_{3}$ crystals on the surface of the microfibres. The scale bar has a height of $200 \mu \mathrm{m}$.

$\mathrm{CaCO}_{3}$ crystals can attach, which was also noticed in microscopic investigations by Homma et al. (2009). This is clearly visible in Figure 8. This is also visible in large cracks, but only when a crack is small enough, the precipitation can cover the whole opening of the crack. Closer to the crack tip, however, there is a lower distance between the crack faces. This gives the opportunity of crack bridging by healing materials inside. Even though almost no healing is visible at the crack surface, the inner part of a crack is healed, resulting in some regain in the mechanical properties.

Storage in an environment with a RH of more than $90 \%$ only showed visual closure of cracks for samples containing SAPs. SAP particles manage to take moisture out of a humid environment and provide it to the cementitious matrix for crack healing. Also cracks of specimens stored at a $\mathrm{RH}$ of $60 \%$ only healed if the samples contained SAPs. This is similar to internal curing and is reflected in regained first-cracking strength, peak strength and MC on samples with 2 vol. $\%$ of PVA fibres (Figure 9).

Figure 9(a) shows the first-cracking strength and the regain in first-cracking strength. The pores left behind by the formerly saturated SAP particles reduce the tensile strength due to a reduced active cross section of the matrix. Samples containing SAP A show a lower firstcracking strength in comparison with the SAP B

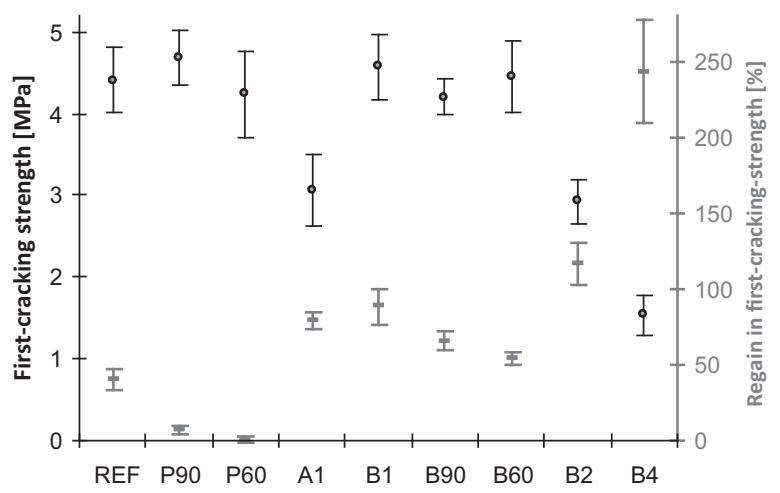

(A)

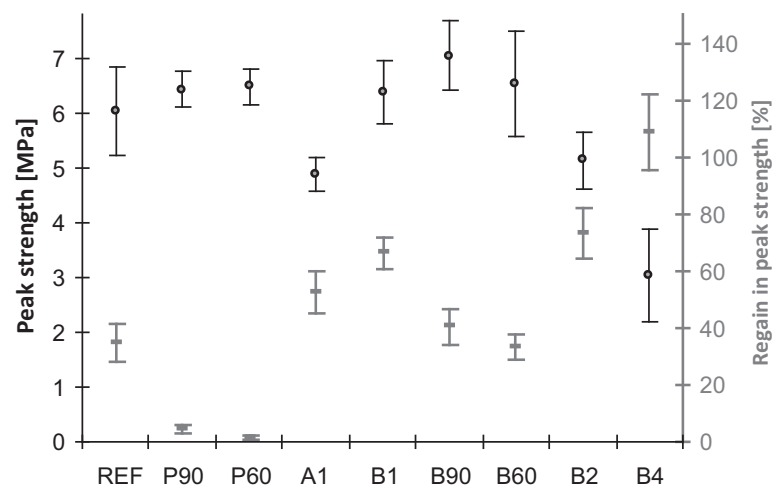

(B)

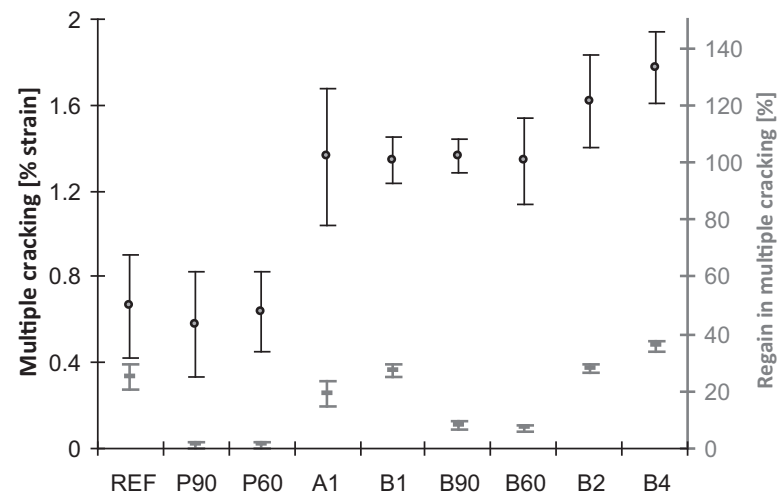

(C)

Figure 9. Mean values and standard deviations for (a) first-cracking strength, (b) peak strength and (c) strain increase during multiple cracking for virgin (black, left axis) and healed specimens (grey, right axis). REF, AI, BI, B2, B4 = wet/dry cycles; P90, B90 = $\mathrm{RH}>90 \% ; \mathrm{P} 60, \mathrm{~B} 60=\mathrm{RH}=60 \%$. REF, P90, P60 containing no SAP; AI containing I m\% of cement weight SAP A; BI, B90, B60 containing I m\% SAP B and B2, B4 containing 2 m\%, 4 m\% SAP B. SAP: superabsorbent polymer; $\mathrm{RH}$ : relative humidity. 
samples due to the lower workability of the fresh cement paste and the smaller particle size. A cross section of a sample containing a large amount of small SAP A particles showed a greater reduction of the available area of solid material due to the formation of macropores than a sample containing the same amount of larger SAP B. Mönnig (2009) also found that the particle size had an influence on the tensile strength. Two mixtures with the same SAP volume (same density of SAP A and SAP B), but with small and large particle sizes, will lead to a reduced tensile strength of the samples with small particles due to more summarised void cross sections in a random plane. Also, the smaller but not perfect spherical particles could act as stressinducing voids (Mönnig, 2009).

A SAP B content of $1 \mathrm{~m} \%$ relative to the cement weight gives analogous properties of the first-cracking strength compared to the REF samples without SAPs. The first-cracking strength, however, decreases with increasing $\mathrm{m} \%$ of SAPs due to a decrease of the surface area. A sample containing $4 \mathrm{~m} \%$ of SAP B was porous and had low mechanical properties (more than 50\% reduction of first-cracking strength). Jensen and Hansen (2002) used 0.3-0.6 m\% SAP to reduce the shrinkage by internal curing and Brüdern and Mechtherine (2010) used $0.4 \mathrm{~m} \%$ SAP. In this investigation, the amount of SAP was altered up to $4 \mathrm{~m} \%$ to investigate the self-healing properties. This mass percent is approximately 10 times higher than the beneficial amount of SAP for internal curing and thus for improving the mechanical properties.

Samples containing SAP particles generally show more regain in the first-cracking strength due to internal curing. When specimens with $1 \mathrm{~m} \%$ of SAP are subjected to wet/dry cycles, the amount of healing is not significantly different from the healing of samples without SAP. Reference samples showed a regain of about $45 \%$, and this is in comparison with Yang (2008) who showed a healing of about $40 \%$ in wet/dry cycles. However, increasing the $\mathrm{m} \%$ of SAP B gives more healing due to more internal curing. Due to further hydration and precipitation of $\mathrm{CaCO}_{3}$, the amount of healing of specimens with 2 and $4 \mathrm{~m} \%$ of SAP B exceeds $100 \%$ for the first-cracking strength. Furthermore, in a RH of more than $90 \%$ and $60 \%$, only samples with SAPs show healing. The moisture uptake by SAPs (cf. DVS measurements in Table 2) seems to be enough to promote self-healing. The best combined result considering the mechanical properties and the healing capacity in all curing conditions is obtained by using $1 \mathrm{~m} \%$ SAP B relative to the cement weight. Also Yang (2008) proved no healing after curing in air (at a $\mathrm{RH}$ of $50 \% \pm 5 \%$ ) for samples without SAPs. The incorporation of SAPs in this investigation, however, promotes self-healing in air of sufficient RH.

For all test series, a strain-hardening effect was noticed. This is due to the MC where bridging action

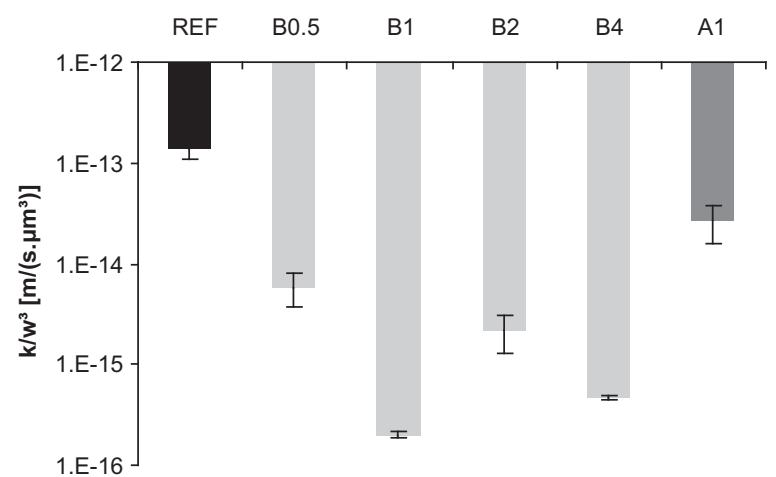

Figure 10. Mean values and standard deviation of the water permeability $k$ over the third power of the crack width $w$ after 30 days. REF: reference; B0.5, BI, B2, B4: SAP B at 0.5, I, 2, 4 $\mathrm{m} \%$ of cement weight and AI: I m\% SAPA. SAP: superabsorbent polymer.

alters the stress. The stress keeps augmenting until a previously created crack widens, lowering the stress. The same conclusions as for the first-cracking strength can be drawn by investigating the peak strength values in Figure 9(b).

SAP particles form macropores due to desorption of the SAPs during cement hydration. Such a system of voids facilitates MC. Samples containing SAPs showed an alteration of the MC behaviour (Figure 9(c)). The same trend of healing is seen for $\mathrm{MC}$ as for the regained first-cracking strength and the peak strength. Besides reopening of the previously formed cracks, even new cracks were formed. Some new cracks were not located in the vicinity of old healed cracks. Healing of the cracks resulted in regained mechanical properties and a total healing of prisms was observed.

\section{Water permeability}

The amount self-sealing was expressed as the water permeability over the third power of the crack width $(\mathrm{k} /$ $\mathrm{w}^{3}$ ), according to the formula of Tsukamoto in equation (8) (Edvardsen, 1999; Tsukamoto and Woener, 1991). In the formula of Tsukamoto, the value of 0.215 for $a_{g}$ is obtained by the mathematical calculation of the lowest residual sum of squares. Edvardsen (1999) calculated a specific value of 0.25 as the experimental $a_{g}$, which is in good accordance to the value found in this investigation (0.215).

Yang (2008) measured a permeability coefficient of $1 \times 10^{-6} \mathrm{~m} / \mathrm{s}$ in a sample with a crack width of 200 $\mu \mathrm{m}$. Dividing the permeability coefficient by the third power of the crack width results in a value of $1.25 \times$ $10^{-13} \mathrm{~m} / \mathrm{s} / \mu \mathrm{m}^{3}$, which is approximately the one found in Figure 10 for cracked reference samples.

A decrease in water permeability is observed in Figure 10 for specimens containing SAPs, in agreement with Lee et al. (2010) who also measured a decrease in 


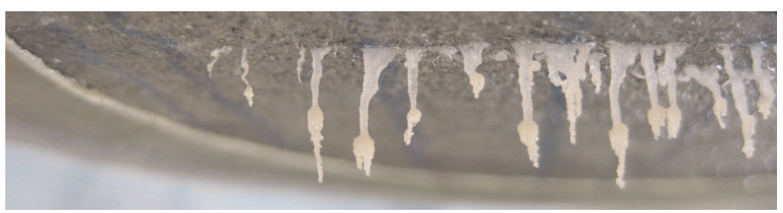

Figure I I. Formation of stalactites with a maximum height of I I mm after a permeability test at the outlet of the crack and a crack width of $75 \mu \mathrm{m}$ containing $2 \mathrm{~m} \%$ SAP B.

SAP: superabsorbent polymer.

permeability. Specimens containing SAP A show a lower decrease due to the smaller particle size. The small size is inappropriate for total sealing of the cracks as the small particles cannot bridge the crack. SAP B in an amount of $1 \mathrm{~m} \%$ relative to the cement weight provided the highest decrease in permeability over time. An amount of $4 \mathrm{~m} \%$ of SAP B caused a coarser matrix (due to the formation of macropores) and lower strength and thus more pathways for water to migrate. Since also the mechanical properties decrease with increasing $\mathrm{m} \%$ of SAP $\mathrm{B}, 1 \mathrm{~m} \%$ of SAP B can be selected as the best option to obtain self-healing mortar.

The outlet of the crack in every specimen showed a large quantity of stalactites after performance of the permeability tests (Figure 11). TGA showed that the stalactites consisted of $\mathrm{CaCO}_{3}$ and washed out hydration products (see Figure 12 for the REF and $\mathrm{B} 1$ samples; A1, B0.5, B2 and B4 are analogous to B1). The degradation temperature of $\mathrm{CaCO}_{3}$ is $700^{\circ} \mathrm{C}-$ $750^{\circ} \mathrm{C}$ (Tiwari, 2008). At this temperature, $\mathrm{CaCO}_{3}$ decomposes to $\mathrm{CaO}$ and $\mathrm{CO}_{2}$. The degradation peak is also visible in the first derivative (black) of the TGA curve (grey) in Figure 12. The degradation of pure $\mathrm{Ca}(\mathrm{OH})_{2}$ starts at $320^{\circ} \mathrm{C}$, peaks at $480^{\circ} \mathrm{C}$ and stops at $510^{\circ} \mathrm{C}$, after Beaudoin et al. (2006), which is also visible in Figure 12. $\mathrm{Ca}(\mathrm{OH})_{2}$ decomposes to the solid $\mathrm{CaO}$ with the formation of $\mathrm{H}_{2} \mathrm{O}$.

TGA was also conducted on virgin SAP, as can be seen in Figure 13, but the degradation peaks of the material $\left(250-450^{\circ} \mathrm{C}, 600^{\circ} \mathrm{C}\right.$ and $\left.900^{\circ} \mathrm{C}\right)$ were not found in the TGA curves of the stalactites, supporting the conclusion that SAPs effectively seal the crack without dissolving or degrading. The peak below $100^{\circ} \mathrm{C}$ can be attributed to adsorbed moisture.

Also, domes were visible on the surface of dried specimens after permeability testing (Figure 14 ). These are pure $\mathrm{CaCO}_{3}$ crystals by the reaction of $\mathrm{CO}_{2}$ dissolved in the $\mathrm{Ca}^{2+}$-rich fluid in the SAPs. The SAPs shrink again by yielding fluid to the precipitation reaction, the matrix and vaporisation. Only the domes are left behind. The crack faces of the specimens showed further hydration and a distinct formation of white crystals.

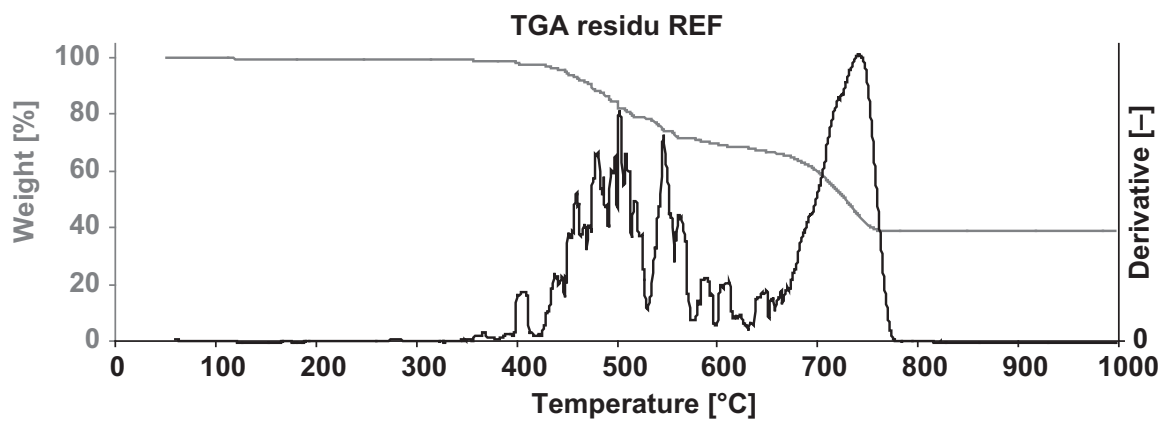

(A)

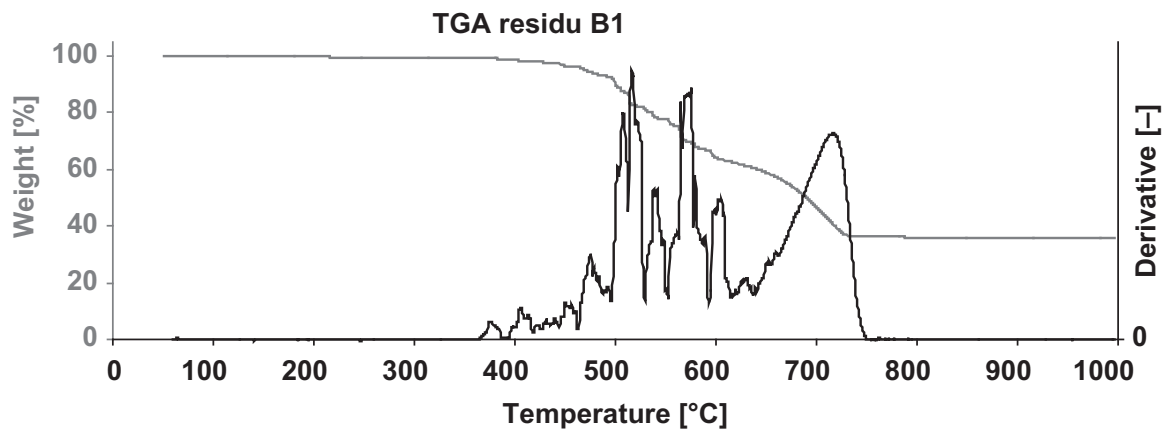

(B)

Figure 12. TGA of the stalactites obtained in the permeability tests in grey with the derivative as a measurement of the weight loss in black of (a) REF samples without SAPs and (b) samples with I m\% SAP B . (TGA of AI, B0.5, B2 and B4 stalactites are analogous to TGA residue $B I$.)

SAP: superabsorbent polymer; RH: relative humidity; TGA: thermogravimetric analysis. 


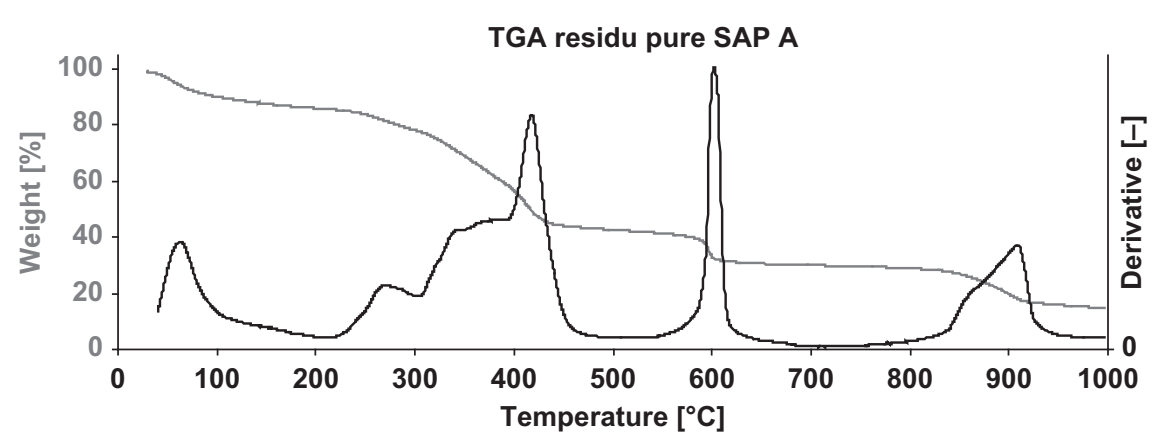

(a)

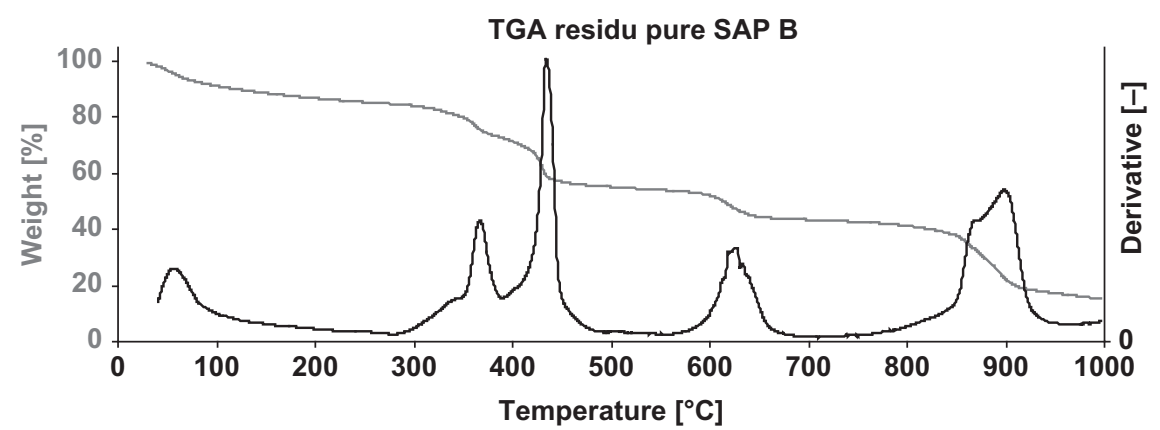

(b)

Figure 13. TGA of pure (a) SAP A and (b) SAP B in grey with the derivative as a measurement of the weight loss in black. SAP: superabsorbent polymer; TGA: thermogravimetric analysis.

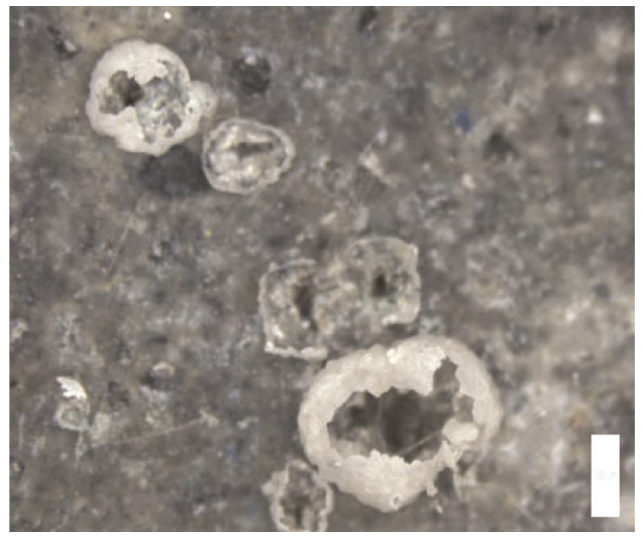

Figure 14. Formation of $\mathrm{CaCO}_{3}$ domes on the sample surface after shrinking of SAPs. The height of the scale bar is $500 \mu \mathrm{m}$. SAP: superabsorbent polymer.

\section{Conclusion}

Microfibre-reinforced concrete is durable and provides reliable tensile ductility and crack-controlling capability to prevent localised cracking failure often observed in concrete structures. SAP particles promote the selfhealing ability by renewed internal curing upon crack formation, and this leads to regain of mechanical properties. When not completely submerged in water, only samples containing SAPs showed self-healing properties due to moisture uptake. SAPs can sustain hydration by yielding their absorbed water and provide water for the precipitation of $\mathrm{CaCO}_{3}$. When cracking occurs and SAP particles are exposed to a humid environment, the particles swell and close the crack. The water permeability diminishes in time, and the cracks are sealed. The combination of microfibres and superabsorbent polymers leads to self-healing of cracks.

SAPs can be useful in regions with almost no rain, or for structures not exposed to direct rainfall, because they absorb the least amount of moisture and provide it to the cementitious matrix for healing. A curing condition with a $\mathrm{RH}$ of more than $90 \%$ gives an equal amount of self-healing compared to wet/dry cycles. In regions with wet/dry cycles, water remains present in the SAPs during the dry periods. Therefore, self-healing can prevail at all times.

SAP A in an amount of $1 \mathrm{~m} \%$ of cement weight induces a reduction of the first-cracking strength due to a lower available effective cross section as an effect of the smaller particle size, whereas the same amount of SAP B did not lead to a significant decrease in strength. Increasing the amount of SAPs from 1 to $2 \mathrm{~m} \%$ or 4 $\mathrm{m} \%$ of the cement weight results in a reduction of both the first-cracking strength and the peak strength. After desorption of SAPs, voids are formed. Such a system of voids facilitates MC. Introducing $1 \mathrm{~m} \%$ of SAP B relative to the cement weight gives the best results, considering the mechanical properties of the virgin material, 
which are similar as for the reference, and the superior self-sealing capacity.

\section{Funding}

This study was supported by Ghent University (BOF project) and the Strategic Initiative Materials Flanders (program Engineered Self-Healing Materials (SHE) and project SECEMIN).

\section{References}

Aldea C, Shah S and Karr A (1999) Effect of cracking on water and chloride permeability of concrete. Materials in Civil Engineering 11(3): 181-187.

Beaudoin JJ, Sato T and Tumidajski PJ (2006) The Thermal decomposition of $\mathrm{Ca}(\mathrm{OH})_{2}$ Polymorphs. In: J. Marchand, B. Bissonnette, R. Gagné, M. Jolin and F. Paradis (eds.) 2nd international symposium on advances in concrete through science and engineering, 11-13 September 2006, RILEM Publications S.A.R.L. Québec, Canada, pp.1-15.

Brüdern AE and Mechtherine V (2010) Multifunctional use of SAP in strain-hardening cement-based composites. In: O.M. Jensen, M.T. Hasholt and S. Laustsen (eds.) International RILEM conference on use of superabsorbent polymers and other new additives in concrete, proceedings PRO 74, 15-18 August 2010, RILEM Publications S.A.R.L. Technical University of Denmark, Lyngby, Denmark.

Edvardsen C1999) Water permeability and autogenous healing of cracks in concrete. ACI Materials Journal 96(4): 448-454.

Granger S, Loukili A, Pijaudier-Cabot G, et al. (2007) Experimental characterisation of the self-healing of cracks in an ultra high performance cementitious material: mechanical tests and acoustic emission analysis. Cement and Concrete Research 37: 1-9.

Homma D, Mihashi H and Nishiwaki T (2009) Self-healing capability of fibre reinforced cementitious composites. Advanced Concrete Technology 7(2): 217-228.

Jensen OM and Hansen PF (2001) Water-entrained cementbased materials: I. Principles and theoretical background. Cement and Concrete Research 31(4): 647-654.

Jensen OM and Hansen PF (2002) Water-entrained cementbased materials: II. Experimental observations. Cement and Concrete Research 32(6): 973-978.
Kim J and Schlangen E (2011) Super Absorbent Polymers to Stimulate Self-Healing in ECC. In: K. van Breugel, G. Ye and Y. Yuan (eds.) 2nd international symposium on service life design for infrastructure, 4-6 October 2010, RILEM Publications S.A.R.L. Bagneux, France, pp. 849858.

Lee HXD, Wong HS and Buenfeld N (2010) Self-sealing cement-based materials using superabsorbent polymers. In: O.M. Jensen, M.T. Hasholt and S. Laustsen (eds.) International RILEM conference on use of superabsorbent polymers and other new additives in concrete, proceedings PRO 74, RILEM Publications S.A.R.L. 15-18 August 2010. Technical University of Denmark, Lyngby, Denmark.

Lepech MD (2006) A paradigm for integrated structures and materials design for sustainable transportation infrastructure. PhD Thesis, Department of Civil Engineering, The University of Michigan, Ann Arbor, MI.

Li VC (2008) Engineered cementitious composites (ECC) material, structural, and durability Performance. In: Nawy E (ed.) Concrete Construction Engineering Handbook. CRC Press, United States.

Mönnig S (2009) Superabsorbing additions in concrete - applications, modelling and comparison of different internal water sources. PhD Thesis, Department of Civil Engineering, The University of Stuttgart, Stuttgart, Germany.

Tanaka D and Fillmore DJ (1979) Kinetics of swelling of gels. Journal of Chemical Physics 70(3): 1214-1218.

ter Heide N (2005) Crack Healing in Hydrating Concrete. MSc Dissertation, Faculty of Civil Engineering and Geosciences, TU Delft University of Technology, Delft, The Netherlands.

Tiwari R (2008) Thermal Techniques for Material Characterization. Ceramic Industry, United States.

Tsukamoto M and Woener JD (1991) Permeability of cracked fibre-reinforced concrete. Darmstadt Concrete 6: 123-135.

Van Tittelboom K, De Belie N, Van Loo D, et al. (2011) Selfhealing efficiency of cementitious materials containing tubular capsules filled with healing agent. Cement and Concrete Composites 33: 497-505.

Yang E-H (2008) Designing added functions in engineered cementitious composites. PhD Thesis, Department of Civil Engineering, The University of Michigan, Ann Arbor, MI. 